\title{
Menjaga Kelestarian Waduk Sermo
}

\author{
Agustin Kencana Putri Mansnandifu ${ }^{1}$, Mariano Zepplin Arus ${ }^{2}$, Theodorus Diaz Alfredo ${ }^{3}$,Prayogo ${ }^{4}$, Evan Joan Candra ${ }^{5}$, I Wayan Angga \\ Saputra $^{6}$, Daniel Axcella Kurniawan ${ }^{7}$, Elisabeth Rena Setya Sawasdee ${ }^{8}$,David Filbert Pradipta ${ }^{9}$, Prasetyo Bagas Wicaksono ${ }^{10}$, Agustinus \\ Aryo Lukisworo ${ }^{11}$ \\ Universitas Atma Jaya Yogyakarta, \\ Jl. Babarsari No.44, Janti, Caturtunggal, Kec. Depok, Kabupaten Sleman, Daerah Istimewa Yogyakarta 55281 \\ Email: agustinus.lukisworo@uajy.ac.id
}

Received 26 November 2021; Revised - ; Accepted for Publication 29 November 2021; Published 30 November 2021

\begin{abstract}
In the KKN Periode 79 of Universitas Atma Jaya Yogyakarta, Kelompok 4 (the Fourth group) of Unit A was assigned to the Hargowilis Village, Kokap, Kulon Progo, Daerah Istimewa Yogyakarta. Due to the spread of Covid-19 pandemic, this period of $K K N$ was held online. Therefore all of this KKN period programs was written upon secondary data. Based on online inquiries, Kelompok 4 has found that Hargowilis has interesting natural resources, and one of it was called WadukSermo. Moreover, our findings shows that Waduk Sermo has a crucial problem regarding to waste. Along with becoming an issue for Waduk Sermo' attractiveness, it also potent to raise ecological problem, especially related to soil fertility. Thus we decided to propose waste management program called $3 R$ that are Reduce, Reuse, and Recycle. We hope that the implementation of this wasteprocessing, aside with increasing environmental hygiene and public health, will also lead to the economic development of Hargowilis.
\end{abstract}

Keywords - Hargowilis, Kokap, Natural Resource, Waduk Sermo, Waste Management.

\begin{abstract}
Abstrak - Dalam KKN Periode 79 yang diselenggarakan oleh Universitas Atma Jaya Yogyakarta, Kelompok 4 yang merupakan bagian dari Unit A ditempatkan di Desa Desa Hargowilis, Kecamatan Kokap, Kabupaten Kulon Progo. Sehubungan dengan permasalahan penyebaran pandemi Covid-19, KKN periode ini dilaksanakan secara daring. Karena itu program-program yang disusun dalam KKN ini dilandasi oleh data sekunder. Melalui penelusuran informasi secara daring tersebut, Kelompok 4 menjumpai bahwa Desa Hargowilis memiliki potensi alam yang menonjol, salah satunya berupa waduk, yakni Waduk Sermo. Lebih lanjut, tampak bahwa Waduk Sermo menghadapi persoalan serius terkait dengan penumpukan sampah. Selain mengurangi keindahan, tumpukan sampah di Waduk Sermo ini juga berisiko mengurangi kesuburan tanah. Karena itu Kelompok 4 memutuskan untuk mengajukan ide pengolahan sampah 3R, yakni Reduce, Reuse, dan Recycle. Penerapan dari pengolahan sampah 3R ini selain diharapkan dapat meningkatkan kebersihan dan kesehatan, juga diharapkan dapat meningkatkan perekonomian warga Desa Hargowilis.
\end{abstract}

Kata Kunci-Hargowilis, Kokap, Potensi Alam, Waduk Sermo, Pengolahan limbah.

\section{Pendahuluan}

Kuliah Kerja Nyata (KKN) merupakan sebuah kegiatan yang dilakukan oleh mahasiswa kemudian didedikasikan kepada masyarakat. Kegiatan ini menggunakan pendekatan lintas keilmuan dan sektoral waktu dan daerah tertentu di Indonesia. Kegiatan KKN juga akan membangun nilai-nilai kepribadian mahasiswa seperti: Kemandirian, tanggung jawab dan etos kerja, kepemimpinan, keuletan, dan kewirausahaan. Dengan beberapa point tersebut para peserta KKN diharapkan dapat membantu mengembangkan potensi pada desa - desa yang dituju. Pelaksanaan KKN periode 79 Universitas Atma Jaya Yogyakarta menggunakan model KKN SOCIETY 5.0 yang dilaksanakan oleh mahasiswa/i secara daring atau onlinedan tidak melakukan penerjunan lapangan secara langsung. Meskipun tidak melakukan penerjuan secara langsung ke lapangan KKN periode 79 tetap dilaksanakan tetap dilaksanakan tanpa mengurangi nilai pengabdian pada masyarakat dengan menggunakan media seperti video ataupun e-book dan buku ajar. Kelompok 4 sendiri mendapatkan kesempatan untuk mengembangkan potensi salah satu desa di Kulon Progo, yaitu Desa Hargowilis.

Desa Hargowilis merupakan salah satu desa yang berada di Kecamatan Kokap, Kabupaten Kulon Progo, Daerah Istimewa Yogyakarta. Desa Hargowilis terletak di wilayah Selatan di antara desa - desa lainya di daerah Kecamatan Kokap ini. Desa Hargowilis Ini memiliki kode Kemendagri 34.01.08.2003 dengan koordinat $7^{\circ} 816446111167208$ LS, $110^{\circ} 11656761169435$ BT. Sebagian besar desa ini berada di daerah perbukitanmenorah yang berada pada ketinggian 500 - 1000 dpl, sehingga sebagian besar daerah tersebut sangat banyak pepohonan. Desa Hargowilis sendiri memiliki luas wilayah sebesar 1453.838 ha. Desa Hargowilis sendiri memiliki ciri khas tersendiri yang merupakan bentangan alam yang sama, yaitu daerah - daerah perbukitan yang luas. Tidak hanya perbukitan saja, namun pada masa sekarang bagian bawah desa ini sudah dijadikan genangan air Waduk yang sudah mulai dibangun pada tahun 1994, dan diresimikan pada tahun 1996. Desa Hargowilis sendiri sudah dikenal baik dengan wisata alamnya yang fenomenal baik didalam negeri (domestik) maupun manca negara. Wisata alam itu sendiri 
merupakan Wisata alam Kalibiru, Suaka Margasatwa Sermo dan Waduk Sermo.

Waduk Sermo merupakan salah satu wisata alam di Kulon Progo yang dikenal sebagai salah satu daerah yang memiliki pesona tersendiri. Daerah Kulon Progo juga dinobatkan sebagai pesona Jawa Tengah. Waduk Sermo merupakan salah satu destinasi wisata yang memiliki danau dengan warna kehijauan yang natural dan dikelilingi bukitbukit, pepohonan, dan rumput yang menutupi seluruh permukaan tanah yang semakin memanjakan mata dan membuat kesan yang sangat nyaman. Udara di sekeliling Wduk Sermo terasa segar dan sejuk, di siang hari pun pengunjung tidak akan merasa panas saat berada di sekitar danau tersebut. Waduk Sermo juga memiliki titik wisata dengan pemandangan hamparan rumput hijau di tepi Waduk, yaitu Camping Spot.

Dengan adanya Camping Spot di wilayah Waduk Sermo dapat menambah nilai plus bagi Desa Hargowilis itu sendiri. Wisatawan tidak secara langsung akan memasarkan keindahan Waduk Sermo melalui media sosial yang berpotensi menarik wisatawan lainnya, sehingga dapat meningkatkan jumlah wisatawan yang berkunjung. Namun fenomena tersebut sendiri dapat menjadi boomerang tersendri jika Desa tidak bersiap akan penangaan kebanjiran wisatawan yang mengunjungi wisata alam tersebut.

Salah satu sumber masalah terbesar dari pembukaan wisata alam kepada publik yaitu permasalahan dalam pengelolahan limbah, terutama limbah sampah yang berada pada lokasi Camping Spot di Waduk Sermo.Camping Spot ini sendiri merupakan potensi terbesar dari wisata alam pada Desa Hargowilis yang harus dijaga denganbaik. Limbah ini berasal dari para wisatawan yang tidak bertanggung jawab saat mengunakan Camping Spot dan meningalkannya dalam keadaan yang kotor. Program ini ditujukan agar Desa meningkatkan pengelolahan limbah yang baik agar tidak kehilangan keindahan dari wisata alam sermo itu sendiri. Selain itu pembuatan lampu jalan harus diperhatikan, terutama pada beberapa akses lokasi yang lebih spesifik (khusus) menjadi lebih mudah dan meningkatkan keinginan wisatawan, sehingga tidak menimbulkan persepsi negatif wisatawan saat berkunjung pertama kali pada Desa Hargowilis.

\section{Metode Pengabdian}

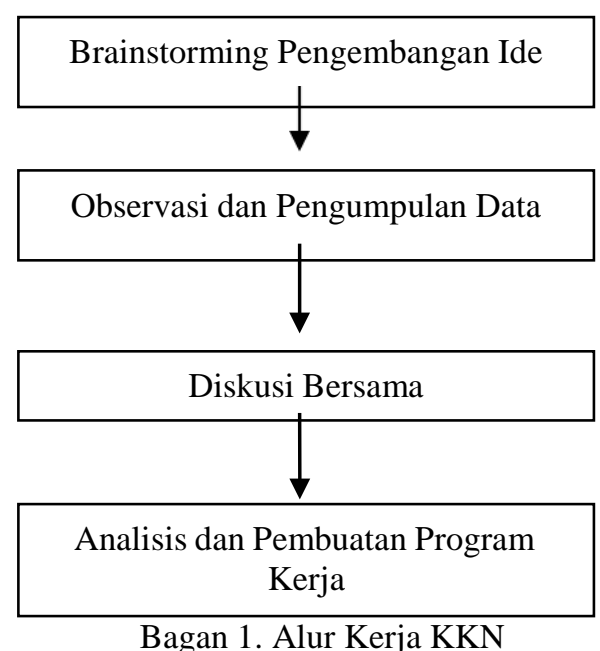

\section{a. Brainstorming Pengembangan Ide}

Ada berbagai macam potensi desa yang dimiliki oleh Desa Hargowilis, Kecamatan Kokap, Kabupaten Kulon Progo. Kelompok menemukan beberapa potensi kekayaan alam yang dapat kami jadikan fokus dalam program KKN. Setelah menentukan fokus dari potensi kekayaan Desa Hargowilis, kelompok akan menuangkan fokus ide potensi dalam sebuah pembahasan.

Kelompok kemudian menentukan potensi desa yang paling menonjol dan akan memberikan dampak positif bagi Desa Hargowilis. Pembahasan mengenai potensi desa paling menonjol inilah yang dituangkan ke dalam buku saku. Bersamaan dengan buku saku tersebut, dilakukan pula penyusunan konsep video yang akan melengkapi usulan ide potensi Desa Hargowilis yang disusun oleh kelompok.

\section{b. Observasi dan Pengumpulan Data}

Observasi adalah kegiatan dimana kelompok melakukan pengamatan tentang potensi desa dan juga problematis yang ada didalamnya. Untuk KKN 5.0 ini observasi yang dilakukan melalui studi pustaka. Tahap berikutnya setelah pengumpulan data maka dilakukan dengan cara peninjauan terhadap sumber-sumber melalui jejaring website yang kemudian data tersebut akan diolah menjadi sebuah produk berupa e-book dan juga video.

\section{c. Diskusi Bersama}

Dengan data yang dikumpulkan dari setiap anggota, yang kemudian didiskusikan bersama-sama secara daring melalui microsoft teams setiap minggunya. Dan dengan ditetapkannya deadline pada setiap progres beserta pembagian untuk setiap penanggung jawabnya, yang bertujuan agar lebih mudah memfollow-up pada tiap progresnya. Pada setiap anggota memberikan idenya masingmasing yang nantinya menjadi topik pembahasanuntuk setiap progres. 
Diskusi secara daring tidak menutup kemungkinan untuk setiap anggota kelompok dapat mengenal satu dengan yang lain, dengan aktif berdiskusi melalui group whatsapp memudahkan interaksi setiap anggota kelompok karena whatsapp itu sendiri menjadi media sosial alat komunikasi yang sering digunakan dan itu sangat memudahkan untuk berkomunikasi dalam keadaan apapun.

\section{d. Analisis dan Pembuatan Program Kerja}

Sebelum menjalankan program KKN Kelompok ini, Kelompok perlu mengidentifikasi permasalahan yangada di Desa Hargowilis, Kokap, Kulon Progo, Yogyakarta. Kelompok mencari Informasi dan menentukan point - point yang perlu diidentifikasi lagi untuk pengembangan potensi desa, sehingga mempermudah breakdown pengerjaan kelompok kedepannya.

Dari beberapa data yang kami kumpulkan akhirnya kami melakukan analisa bersama secara online melalui Ms.Team. Kelompok kami berhasil menemukan fokus permasalahan dan juga potensi desa yang bisa dikembangkan lebih lanjut. Program KKN Kelompok akan berfokus pada buku saku elektronik (e-book) dan pembuatanvideo. Dengan penyusunan timeline dan juga deadline mingguan sebagai acuan dan juga pengawasan dan juga penanggung jawab, seperti evaluasi setiap minggunya yang akhirnya disusun menjadi program Laporan KKN Kelompok.

\section{Hasil dan Pembahasan}

\section{A. Potensi Desa Hargowilis}

\section{Wisata Alam Kalibiru}

Wisata Alam Kalibiru merupakan salah satu destinasi wisata alam yang berada di Kalibiru, Desa Hargowilis, Kokap, Kulon Progo yang menawarkan pemandangan alam dari atas perbukitan menoreh berupa lembah rindang menyatu dengan indahnya Waduk Sermo. Kegiatan utama yang ditawarkan di dalam WisataAlam Kalibiru adalah berfoto pada spot-spot foto yang telah disediakan oleh pihak pengelola seperti dari spot panggung, spot gantole, spot kursi langit, foto sepeda, spot pohon, spot love, dan lain-lain. Selain itu wisata Kalibiru ini memiliki potensi untuk dapat menawarkan penginapan kepada para wisatawan dengan pemandangan spot alam yang menarik.

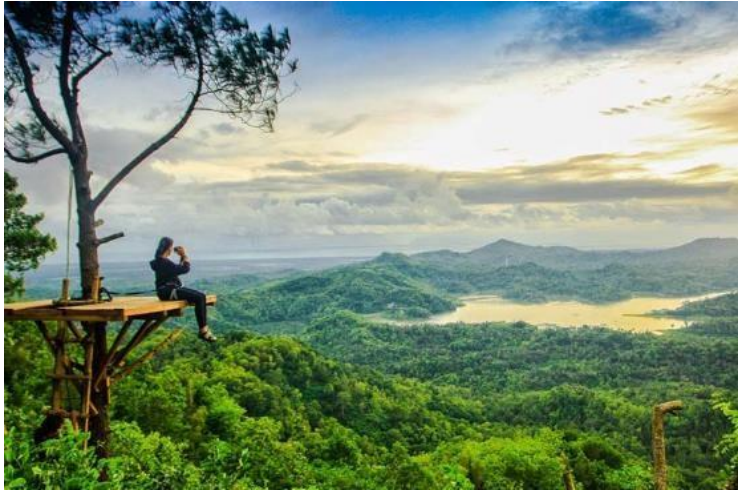

Gambar 1. Kalibiru

\section{Wisata Alam Waduk Sermo}

Waduk Sermo merupakan sebuah bendungan air yang sudah berdiri selama 25 tahun sejak dibangun pada tahun 1994 dan akhirnya diresmikan oleh Presiden Soeharto pada tanggal 20 November 1996, menjadi sumber air bersih untuk keperluan Perusahaan Daerah Air Minum serta digunakan sebagai suplai air untuk sistem irigasi sawah. Selain menjadi sumber pengairan bagi sistem irigasi sawah, Waduk Sermo juga menjadi sebuah tempat wisata yang sering dikunjungi warga lokalmaupun turis karena suasana alam yang menenangkan disekitar Waduk Sermo seringkalo dijadikan area camping dan spot foto yang menarik.

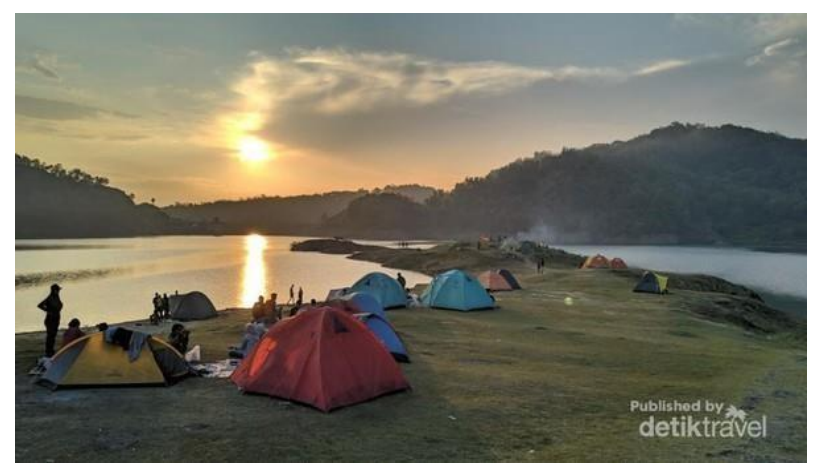

Gambar 2. Waduk Sermo

\section{Wisata Alam Suaka Margasatwa Sermo}

Suaka Margasatwa Sermo merupakan salah satu wilayah konservasi yang berada di Daerah Istimewa Yogyakarta yang menyimpan dan melindungi berbagai macam flora dan fauna yang dianggap sebagai flora dan fauna yang terancam punah dan menjadi salah satu profil atau ikon dari kekayaan flora dan fauna Indonesia. Fungsi utama suaka margasatwa adalah untuk melindungi satwasatwa yang dianggap terancam punah dengan tetap memperhatikan kenyamanan para pengunjung. Di Suaka Margasata Sermo ini 35 spesies flora yang dilindungi termasuk juga dengan beberapa macam fauna dari kelas aves (burung). 


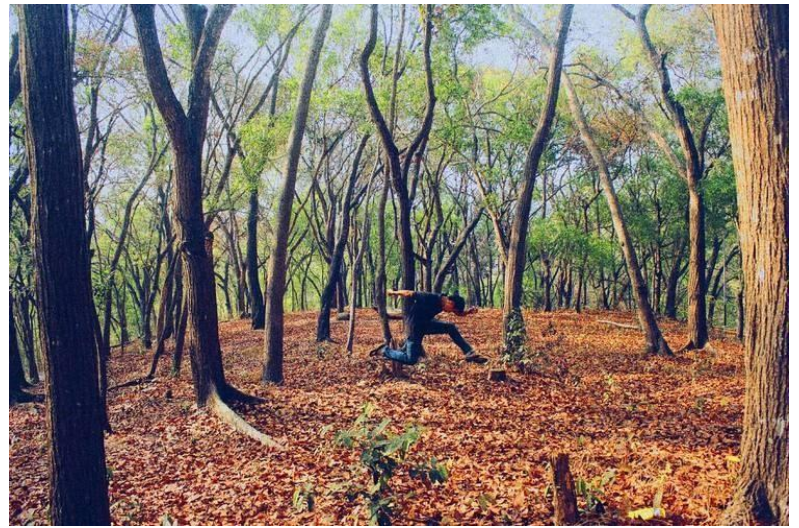

Gambar 3. Suaka Margasatwa Sermo

\section{Pertanian dan Perkebunan}

Desa Hargowilis berpotensi bagi perkebunan ubi jalar dan juga kelapa. Berbagai jenis ubi jalar yang biasanya ditemukan di Indonesia memiliki keunikan dan manfaatnya masing-masing, kebanyakan jenis ubi jalar dapat berpotensi dikembangkan di wilayah Desa Hargowilis. Selain ubi jalar, pohon kelapa juga berpotensi besar untuk dikembangkan di wilayah Desa Hargowilis. Pengembangan pohon kelapa memberikan banyak sekali manfaat mulai dari air dan daging kelapa yang dapat dikonsumsi untuk melancarkan pencernaan dan pencegahan diabetes, batang pohon kelapa yang dapat dijadikan material konstruksi, serta batok kelapa yang dapat dijadikan kerajinan local, aksesoris, serta wadah makanan dan minuman.

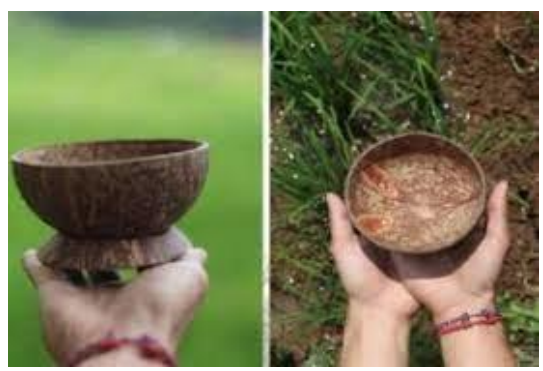

Gambar 4. Pemanfaatan Batok Kelapa

\section{B. Limbah Sampah Waduk Sermo}

Dari kegiatan Kuliah Kerja Nyata (KKN) diwilayah Desa Hargowilis ini, diperoleh hasil berupa e-book dan video yang berfokus pada pengolahan limbah sampah dikawasan wisata Waduk Sermo. E-book dan video hasil KKN ini bertujuan untuk lebih meng-edukasi masyarakat Desa Hargowilis mengenai bagaimana cara pengolahan limbah sampah serta alternatif yang dapat diambil untuk memanfaatkan kembali sampah-sampah tersebut. Dengan adanya penyelesaian mengenai limbah sampah ini, diharapkan kawasan-kawasan wisata dapat menjadi lokasi wisata yang nyaman bagi para pengunjungnya dan destinasi wisata di Desa Hargowilis semakin berkembang.

\section{2 Fokus Masalah}

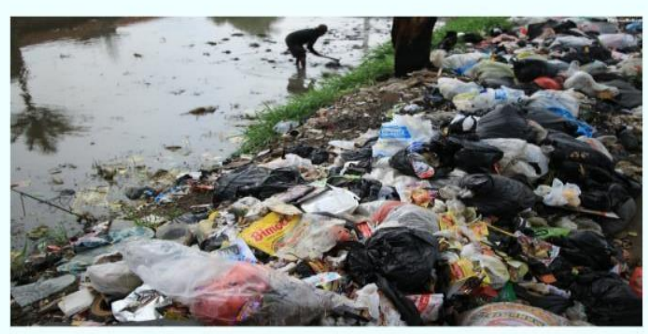

Begitupun juga pembuangan limbah di lingkungan darat atau pada tanah. Pembuangan limbah bisa mencemari tanah seperti membuang sampah sembarangan, dan mengubur sampah kedalam tanah. Jika sampah dikubur dalam tanah maka tanh tersebut akan merusak kesuburan pada tidak

Adapun masalah yang terjadi adalah sampah-sampah yang berserakan di daerah wisata Waduk Sermo. Limbah yang dibuang pun mermacam-macam jenisnya. Limbah sampah yang berserakan di Kawasan wisata ini diantaranya adalah pembuangan limbah di air dan tanah berupa sampahsampah plastik, karet, logam, bahan limbah laboratium, dan lain sebagainya.

Limbah tersebut mengontaminasi saluran air dan berpotensi besar menyebabkan kerusakan pada kehidupan lingkungan sungai. Selain itu, limbah tersebut juga menyebabkan tanah menjadi tidak subur lagi. Kemudian selain limbah sampah yang berserakan, pembuangan limbah di udara juga turut menyumbang ketidaknyamanan lingkungan di sekitar Waduk Sermo. Hal ini bersumber pada proses pembakaran sampah di tempat terbuka, yang berpotensi menyebabkan penyakit pada pernafasan.

\section{Pengolahan Limbah Sampah}

Berkaitan dengan eksistensi limbah sampah di Waduk Sermo, tentu saja upaya pencegahan menjadi salah satu langkah yang perlu untuk dilakukan. Hal ini dapat dilakukan melalui pengetatan aturan. Misalnya mengenai larangan membawa makanan/minuman yang berpotensi menimbulkan sampah plastik, menggalakkan kampanye kebersihan dengan memasang poster-poster tentang perilaku baik terhadap sampah, dan juga menyediakan tempatsampah yang terpisah antara organic dan anorganik dengan kuantitas yang memadai bagi seluruh pengunjung.

Kemudian langkah tersebut juga perlu ditopang dengan sosialisasi kepada masyarakat sekitar mengenai bahaya limbah sampah ini, baik bagi kehidupan masyarakat maupun bagi potensi Desa Hargowilis. Diharapkan sosialisasi ini 
dapat meningkatkan kesadaran masyarakat mengenai pentingnya menjaga kebersihan lingkungan dari limbah sampah. Karena keterlibatan warga masyarakat sekitar menjadi salah satu hal yang penting untuk dapat mengatasi persoalan limbah sampah tersebut.

Lebih lanjut, terkait dengan kondisi yang ada, perlu dilakukan langkah pengolahan limbah sampah. Adapun proses pengolahan limbah sampah tersebut dapat mengadopsi pola 3R, reduce, reuse, dan recycle. Ketiga aspek tersebut, dapat dipahami sebagai berikut:

- $\quad$ Reduce (Mengurangi) yaitu membeli produk yang tahan lama dan mengurangi potensi penambahan sampah.

- Reuse (Penggunaan Kembali) yaitu menggunakan kembali barang yang masih layak pakai.

- $\quad$ Recycle (Daur ulang) yaitu memilah sampah sesuai jenis seperti organik dan anorganik, lalu mendaur ulang sampah tersebut sesuai dengan kategorinya. Dengan alat tambahhan dan kreativitas masyarakat, sampah-sampah yang masih layak dapat diolah kembali menjadi sesuatu yang bermanfaat. Langkah ini dapat sekaligus mencakup Reduce sampah yang ada dan Recycle sampah yang masih layak diolah.

- Pembuatan Pupuk Kompos dengan mengolah sampah yang dapat dijadikan kompos, terutama sampah organik.

- Membuang sisa sampah yang tidak diolah ke TPA

Apabila konsep-konsep pengolahan limbah sampah diatas dapat dilaksanakan oleh masyarakat, diharapkan akan muncul lingkungan yang lebih bersih, serta kehidupan masyarakat yang lebih sehat. Kemudian jika dihubungkan dengan persoalan yang lebih luas, maka mengurangi limbah sampah akan memiliki implikasi positif bagi kelestarian bumi. Misalnya untuk mengurangi risiko global warming.

\section{Aspek Ekonomis Pengentasan Limbah Sampah}

Adapun pengolahan dan pencegahan sampah itu sendiri, selain menjadi bagian dari upaya untuk mengatasi berbagai persoalan yang mungkin ditimbulkan baik secara sosial maupun ekologis, juga dapat dikembangkan menjadi sesuatu yang memiliki nilai ekonomis. Contohnya mengganti pemakaian plastik menjadi batok kelapa sebagai wadah makanan atau minuman. Selain itu juga dapat dilakukan melalui produksi tumblr minum dengan corak khas sebagai langkah mengurangi penggunaan botol plastik. Kedua hal tersebut, bahkan dapat menambah daya tarik wisata yang khas dan dapat ditawarkan sebagai bagian dari promosi wisata Waduk Sermo.

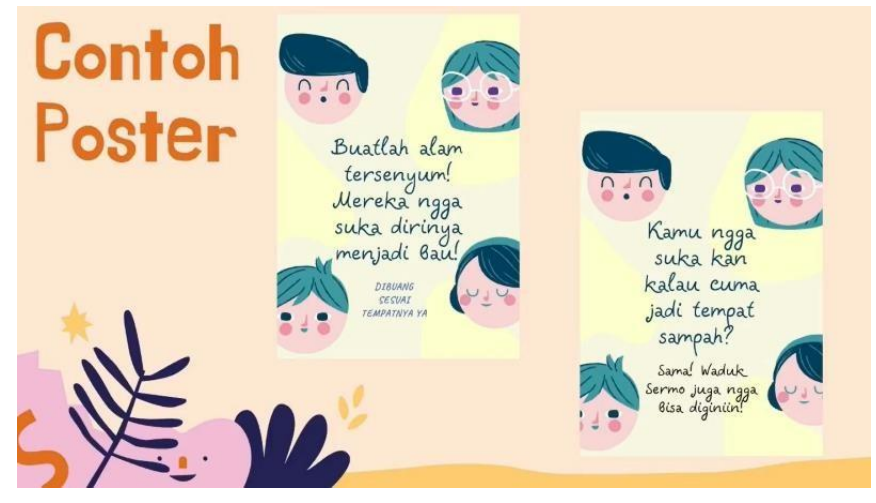

Gambar 6. Contoh Poster

Kemudian selain produksi alat minum, terdapat pula potensi ekonomis lain dari proses pengentasan persoalan limbah sampah di Waduk Sermo, yakni dengan memanfaatkan bank sampah yang sudah banyak eksis di Yogyakarta. Untuk dapat merealisasikan hal ini, langkah yang dapat ditempuh adalah dengan melakukan pembersihandan pemilahan sampah. Lebih lanjut, dalam kondisi terjadi penumpukan sampah dalam jumlah yang besar, perlu adanya keterlibatan dari warga masyarakat Desa Hargowilis. Karena tentu aktivitas ini akan memerlukan sumber daya manusia dalam jumlah yang besar pula. Pembersihan sampah secara massal dilakukan untuk melokalisir keberadaan sampah di berbagai titik di Waduk Sermo. Kemudian ketika sampah sudah terkumpul, pemilahan sampah baru dapat dilakukan. Beberapa sampah seperti plastik, kaca, kaleng dan kertas adalah beberapa jenis yang dapat dijual kepada bank sampah.

Apabila kedua hal tersebut, yakni produksi alat minum dan penjualan sampah ke bank sampah dapat dilakukan, maka akan muncul nilai ekonomis dari upaya pengentasan sampah di sekitar Waduk Sermo. Bahkan selain itu, karena kedua aktivitas ini kemungkinan besar akan memerlukan sumber daya manusia dalam jumlah yang besar pula, maka tentunya manfaat dari kedua hal tersebut juga akan dirasakanbanyak pihak secara kolektif. Hal ini tentu dapat menjadi landasan untuk mempererat solidaritas diantara warga Desa Hargowilis.

\section{KESIMPULAN}

Desa Hargowilis merupakan salah satu desa yang berada di Kecamatan Kokap, Kabupaten Kulon Progo. Letak geografis dari Desa Hargowilis relatif dekat dengan pantai. Terdapat berbagai macam potensi yang dimiliki oleh Desa Hargowilis, yang meliputi potensi wisata alam dan potensi pertanian dan perkebunan.

Dari segi wisata alam, potensi dari Desa Hargowilis terletak pada 2 tempat, yaitu Waduk Sermo, Suaka Margasatwa Sermo, dan Wisata Alam Kalibiru. Dari segi pertanian dan perkebunan, terdapat 2 hasil perkebunan yang sangat dikenal di area Desa Hargowilis, yaitu ubi dan kelapa. Kelapa sangat terkenal di Kecamatan Kokap, khususnya Desa Hargowilis karena kondisi iklim, tanah, dan suhu udara 
yang cocok dengan kondisi yang dibutuhkan oleh tanaman kelapa untuk tumbuh.

Dari beberapa potensi yang dimiliki, kami berfokus pada potensi wisata alam yang dimiliki, khususnya potensi yang terdapat pada waduk Sermo. Untuk mengembangkan potensi ini, terdapat satu persoalan yang perlu untuk diatasi, yakni terkait dengan permasalahan limbah. Hal ini tampak dari penumpukan berbagai macam sampah di sekitar Waduk Sermo. Selain dapat mengganggu keindahan alam yang ditawarkan, sampah-sampah ini juga berpotensi menimbulkan persoalan ekologis, terkait dengan kesuburan tanah. Karena itu diperlukan solusi melalui pengolahan sampah 3R.

Adapun pengolahan limbah sampah $3 \mathrm{R}$ tersebut, tentu dapat membuat waduk menjadi lebih terawat. Apabila waduk terawat tentu daya tarik wisata dari waduk tersebut akan berkembang. Selain itu, teratasinya persoalan limbah sampah juga akan memiliki implikasi positif terhadap kebersihan kesehatan warga masyarakat di Desa Hargowilis. Lebih lanjut, terdapat pula implikasi positif lain bagi warga masyarakat Desa Hargowilis, jika kesadaran terhadap limbah sampah ditingkatkan. Hal ini berupa potensi ekonomi yang dapat dirasakan secara kolektif oleh warga desa Hargowilis.

\section{UCAPAN TERIMAKASIH}

Terima kasih sebesar-besarnya kami ucapkan kepada Universitas Atma Jaya Yogyakarta selaku penyelenggara KKN 79 dengan metode 5.0 sehingga output yang kami berikan berupa E-book dan Video dapat disalurkan dan sekiranya berguna untuk masyarakat utamanya di Kecamatan Kokap.

\section{Daftar Pustaka}

[1] Samadi, 2002, Geografi, Yhudistira: Yogyakarta.

[2] www.budaya.jogprov.go.id, diakses tanggal 14 April 2021

[3] www.republika.co.id ,diakses tanggal 14 April 2021

[4] www.tempatwisataunik.com, Elsa F. Bena, diakses tanggal 14 April 2021

[5] www.pendidikan.co.id, diakses tanggal 1 Mei 2021

[6] https://dlh.kulonprogokab.go.id/detil/535/sepenggalkisah-mengenai-suaka-margasatwa-sermo-marilestarikan-bersama, diakses pada 30 Maret 2021.

[7] Darya, I Gusti Putu , 2019, Akuntansi Manajemen, Ponorogo: Uwais Inspirasi Indonesia.

[8] Rachmawati, Hilda, 2021, Komunikasi Merek Di Media Sosial \& Penerapannya Pada TV Berita, Yogyakarta: CV Budi Utama.

[9] Yudha, R Eprilurahman, IA Muhtianda, F Ekarinid dan OC Ningsih, 2015, Keanekaragaman Spesies Amfibi dan Reptil Di Kawasan Suaka Margasatwa Sermo Daerah Istimewa Yogyakarta Jurnal MIPA 38
(1) (2015): 8-13, Yogyakarta: Fakultas Biologi, Universitas Gadjah Mada, Yogyakarta.

[10] Muhammad Sulaiman, 2019, Pengawasan Pencemaran Lingkungan (STUDI KASUS LIMBAH INDUSTRI KELAPA SAWIT DI KABUPATEN INDRAGIRI HULU) JOM FISIP Vol. 6: Edisi I Januari-Juni 2019, Riau: Fakultas Ilmu Sosial danIlmu Politik Universitas Riau.

\section{PENULIS}

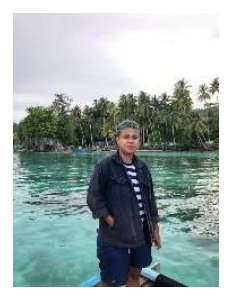

Agustin Kencana Putri Mansnandifu, Prodi Hukum,

Fakultas Hukum,

Universitas Atma Jaya Yogyakarta.

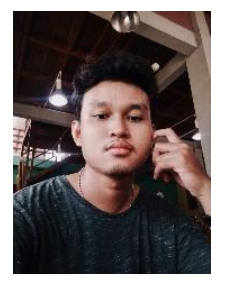

Mariano Zepplin Arus,

Prodi Manajemen,

Fakultas Bisnis dan Ekonomi,

Universitas Atma Jaya Yogyakarta.

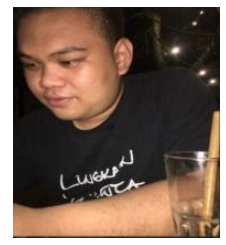

Theodorus Diaz Alfredo,

Prodi Hukum,

Fakultas Hukum,

Universitas Atma Jaya Yogyakarta.

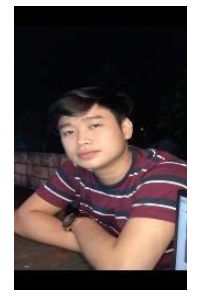

Prayogo,

Prodi Ekonomi Pembangunan,

Fakultas Bisnis dan Ekonomi,

Universitas Atma Jaya Yogyakarta

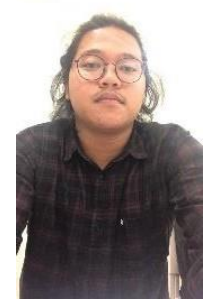

Evan Joan Candra,

Prodi Teknik Sipil,

Fakultas Teknik,

Universitas Atma Jaya Yogyakarta

I Wayan Angga Saputra,

Prodi Teknik Industri,

Fakultas Teknologi Industri,

Universitas Atma Jaya Yogyakarta. 


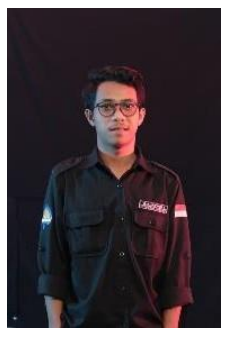

Daniel Axcella Kurniawan,

Prodi Informatika,

Fakultas Teknologi Industri,

Universitas Atma Jaya Yogyakarta

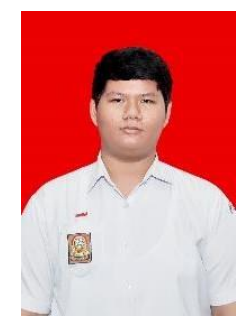

Elisabeth Rena Setya Sawasdee, Prodi Ilmu Komunikasi,

Fakultas Ilmu Sosial dan Politik,

Universitas Atma Jaya Yogyakarta

David Filbert Pradipta,

Prodi Ilmu Komunikasi,

Fakultas Ilmu Sosial dan Politik,

Universitas Atma Jaya Yogyakarta

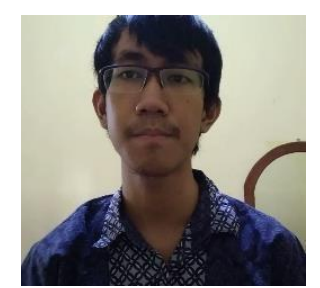

Prasetyo Bagas Wicaksono,

Prodi Sistem Informasi,

Fakultas Teknik Industri,

Universitas Atma Jaya Yogyakarta

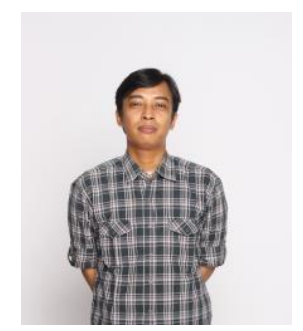

Agustinus Aryo Lukisworo,

Prodi Sosiologi,

Fakultas Ilmu Sosial \& Ilmu Politik,

Universitas Atma Jaya Yogyakarta 